\title{
High levels of whole-body energy expenditure are associated with a lower coupling of skeletal muscle mitochondria in C57B1/6 mice
}

Citation for published version (APA):

van den Berg, S. A., Nabben, M., Bijland, S., Voshol, P. J., van Klinken, J. B., Havekes, L. M., Romijn, H. A., Hoeks, J., Hesselink, M. K., Schrauwen, P., \& van Dijk, K. W. (2010). High levels of whole-body energy expenditure are associated with a lower coupling of skeletal muscle mitochondria in C57B1/6 mice. Metabolism-Clinical and Experimental, 59(11), 1612-1618.

https://doi.org/10.1016/j.metabol.2010.03.008

Document status and date:

Published: 01/11/2010

DOI:

10.1016/j.metabol.2010.03.008

Document Version:

Publisher's PDF, also known as Version of record

Document license:

Taverne

Please check the document version of this publication:

- A submitted manuscript is the version of the article upon submission and before peer-review. There can be important differences between the submitted version and the official published version of record.

People interested in the research are advised to contact the author for the final version of the publication, or visit the DOI to the publisher's website.

- The final author version and the galley proof are versions of the publication after peer review.

- The final published version features the final layout of the paper including the volume, issue and page numbers.

Link to publication

\footnotetext{
General rights rights.

- You may freely distribute the URL identifying the publication in the public portal. please follow below link for the End User Agreement:

www.umlib.nl/taverne-license

Take down policy

If you believe that this document breaches copyright please contact us at:

repository@maastrichtuniversity.nl

providing details and we will investigate your claim.
}

Copyright and moral rights for the publications made accessible in the public portal are retained by the authors and/or other copyright owners and it is a condition of accessing publications that users recognise and abide by the legal requirements associated with these

- Users may download and print one copy of any publication from the public portal for the purpose of private study or research.

- You may not further distribute the material or use it for any profit-making activity or commercial gain

If the publication is distributed under the terms of Article $25 \mathrm{fa}$ of the Dutch Copyright Act, indicated by the "Taverne" license above, 


\title{
High levels of whole-body energy expenditure are associated with a lower coupling of skeletal muscle mitochondria in $\mathrm{C} 57 \mathrm{Bl} / 6$ mice
}

\author{
Sjoerd A.A. van den Berg ${ }^{\mathrm{a}, *, 1}$, Miranda Nabben ${ }^{\mathrm{b}, 1}$, Silvia Bijland ${ }^{\mathrm{a}}$, Peter J. Voshol ${ }^{\mathrm{c}}$, \\ Jan Bert van Klinken ${ }^{\mathrm{a}}$, Louis M. Havekes ${ }^{\mathrm{d}, \mathrm{e}, \mathrm{f}}$, Johannes A. Romijn ${ }^{\mathrm{c}}$, Joris Hoeks ${ }^{\mathrm{b}}$, \\ Matthijs K. Hesselink ${ }^{\mathrm{g}}$, Patrick Schrauwen ${ }^{\mathrm{b}}$, Ko Willems van Dijk ${ }^{\mathrm{a}, \mathrm{c}}$ \\ ${ }^{a}$ Department of Human Genetics, Leiden University Medical Center, Leiden 2333 ZC, The Netherlands \\ ${ }^{\mathrm{b}}$ Department of Human Biology, Nutrim, School for Nutrition, Toxicology and Metabolism, \\ Maastricht University Medical Center, Maastricht 6200 MD, The Netherlands \\ ${ }^{\mathrm{c}}$ Department of Endocrinology and Metabolic Diseases, Leiden University Medical Center, Leiden 2333 ZC, The Netherlands \\ ${ }^{\mathrm{d}}$ Department of General Internal Medicine, Leiden University Medical Center, Leiden 2333 ZC, The Netherlands \\ ${ }^{\mathrm{e}}$ TNO Quality of Life, Gaubius Laboratory, Leiden 2301 CE, The Netherlands \\ ${ }_{\mathrm{f}}^{\mathrm{f}}$ Department of Cardiology, Leiden University Medical Center, Leiden 2333 ZC, The Netherlands \\ ${ }^{\mathrm{g}}$ Department of Human Movement Sciences, Nutrim, School for Nutrition, Toxicology and Metabolism, \\ Maastricht University Medical Center, Maastricht 6200 MD, The Netherlands \\ Received 22 December 2009; accepted 15 March 2010
}

\begin{abstract}
Considerable variation in energy expenditure is observed in C57B1/6 mice on a high-fat diet. Because muscle tissue is a major determinant of whole-body energy expenditure, we set out to determine the variation in energy expenditure and its possible association with skeletal muscle mitochondrial function upon high-fat diet intervention. Metabolic cages using indirect calorimetry were used to assess whole-body energy metabolism in C57B1/6 male mice during the first 3 days of high-fat diet intervention. Mice were grouped in a negative or positive residual nocturnal energy expenditure group after correction of total nocturnal energy expenditure for body mass by residual analysis. The positive residual energy expenditure group was characterized by higher uncorrected total nocturnal energy expenditure and food intake. On day 7, mitochondria were isolated from the skeletal muscle of the hind limb. Mitochondrial density was determined by mitochondrial protein content and did not differ between the positive and negative residual energy expenditure groups. Using high-resolution respirometry, mitochondrial oxidative function was assessed using various substrates. Mitochondria from the positive residual energy expenditure group were characterized by a lower adenosine diphosphate-stimulated respiration and lower respiratory control rates using palmitoyl-coenzyme A as substrate. These results indicate that reduced mitochondrial coupling is associated with positive residual energy expenditure and high rates of total energy expenditure in vivo.
\end{abstract}

(C) 2010 Elsevier Inc. All rights reserved.

\section{Introduction}

The C57Bl/6 mouse model has been used extensively in nutritional studies because of its obesogenic nature upon high-fat feeding. However, although $\mathrm{C} 57 \mathrm{Bl} / 6$ mice are genetically identical, considerable interindividual variation exists in their metabolic response to a high-fat diet and subsequent development of obesity [1]. Hypercaloric energy

\footnotetext{
* Corresponding author.

E-mail address: svdberg@lumc.nl (S.A.A. van den Berg).

1 Both authors contributed equally to this work.
}

intake (EI) has been shown in some $[2,3]$ but not all experimental diet-induced obesity (DIO) models [4-7]. However, in addition to hypercaloric EI, low levels of EE might contribute to the development of DIO. It has been demonstrated that low levels of EE predispose to body weight gain in Pima Indians [8,9], although a paradoxical positive correlation between EE and weight gain has also been established in a number of other studies [10,11]. To a major extent, EE is determined by mitochondrial respiration in skeletal muscle $[12,13]$. In addition, insufficient oxidative capacity has been demonstrated to induce mitochondrial stress and ultimately mitochondrial dysfunction [14-16]. In 
this study, we assessed whether differences in skeletal muscle mitochondrial performance could explain the differences in whole-body EE upon high-fat feeding in C57B1/6 mice. A short-term approach, using only 1 week of high-fat diet intervention, was chosen to assess whole-body as well as mitochondrial oxidative properties independent of DIO and insulin resistance. Changes in whole-body oxygen uptake and carbon dioxide production, EI, and activity upon high-fat feeding were addressed by indirect calorimetry and metabolic cage analysis. High-resolution respirometry analysis was performed to determine respiratory capacity and degree of coupling of isolated skeletal muscle mitochondria on both carbohydrate and lipid substrates [17,18]. Positive residual nocturnal energy expenditure (EE) in response to the high-fat diet was found to be associated with a low degree of mitochondrial coupling, which explains at least in part the higher degree of whole-body EE in these mice.

\section{Methods}

\subsection{Animals and housing}

Male C57Bl/6J mice were obtained from Charles River Laboratories at an age of 8 weeks and acclimatized up to an age of 12 weeks at the Leiden University Medical Center animal facility. Animals were housed individually in a controlled environment $\left(21^{\circ} \mathrm{C}, 40 \%-50 \%\right.$ humidity) under a 12-hour photoperiod (7:00 AM-7:00 PM). Food and tap water were available ad libitum during the whole experiment. At an age of 14 weeks, animals were switched to a high-fat palm oil diet ( $45 \%$ energy in the form of fat, D12451; Research Diet Services, Wijk bij Duurstede, the Netherlands). The switch was performed in an automated metabolic cage setup using indirect calorimetry to assess acute changes in whole-body respiratory metabolism upon high-fat feeding.

\subsection{Indirect calorimetry}

A total of 20 mice were subjected to individual indirect calorimetry measurements for a period of 4 consecutive days (Comprehensive Laboratory Animal Monitoring System, Columbus Instruments, Columbus, $\mathrm{OH})[19,20]$. A period of 24 hours was included at the start of the experiment to allow acclimatization of the animals to the cages. Experimental analysis started at 9:00 AM and continued for 72 hours. Analyzed parameters included real-time food and water intake and activity. Oxygen consumption and carbon dioxide production rates measurements were performed at intervals of 7 minutes throughout the whole period. Respiratory exchange rate (RER) as a measure for metabolic substrate choice was calculated as the ratio between carbon dioxide production and oxygen consumption. Carbohydrate oxidation (CHox) and fat oxidation (Fox) rates were calculated according to Perronnet and Massicote [21]. Total EE was calculated from the sum of CHox and Fox. Nocturnal EE and diurnal EE were analyzed separately.

\subsection{Tissue collection}

Mice were anesthetized and killed by cervical dislocation. Skeletal muscle from both hind limbs was rapidly dissected and placed into ice-cold mitochondrial isolation medium containing $100 \mathrm{mmol} / \mathrm{L}$ sucrose, $50 \mathrm{mmol} / \mathrm{L} \mathrm{KCL}, 20 \mathrm{mmol} / \mathrm{L}$ $\mathrm{K}^{+}$-TES, $1 \mathrm{mmol} / \mathrm{L}$ EDTA, and $0.2 \%(\mathrm{wt} / \mathrm{vol})$ bovine serum albumin (BSA). Both tibialis anterior muscles were held separately and frozen in liquid nitrogen for further analysis of uncoupling protein 3 (UCP3) protein mitochondrial density protein markers. The tibialis anterior muscle represents the mixed composition of the other hind limb muscles used for the mitochondrial isolation.

\subsection{Mitochondrial isolation}

After dissection, skeletal muscle was freed from adipose and connective tissue, minced with precooled scissors, and homogenized in a Potter homogenizer, whereafter proteinase (Subtilisin, $0.7 \mathrm{mg} / \mathrm{g}$ tissue; Sigma-Aldrich, St Louis, MO) was added. Homogenates were centrifuged, and mitochondrial protein concentrations were determined using fluorescamine (Fluram; Fluka, Zwijndrecht, the Netherlands) with BSA as a standard.

\subsection{Mitochondrial respiration}

Mitochondrial isolation was performed as described before [22]. Mitochondrial respiration was measured using a 2-chamber Oxygraph (Oroboros Instruments, Innsbruck, Austria) as described before [23]. Freshly isolated mitochondria $(0.2 \mathrm{mg}$ mitochondrial protein for pyruvate and 0.5 $\mathrm{mg}$ for carnitine + palmitoyl-coenzyme A [CoA]) were added into the chambers containing respiration medium (100 $\mathrm{mmol} / \mathrm{L}$ sucrose, $20 \mathrm{mmol} / \mathrm{L} \mathrm{K}^{+}$-TES [pH 7.2], $50 \mathrm{mmol} / \mathrm{L}$ $\mathrm{KCL}, 2 \mathrm{mmol} / \mathrm{L} \mathrm{MgCl}_{2}, 1 \mathrm{mmol} / \mathrm{L}$ EDTA, $4 \mathrm{mmol} / \mathrm{L}$ $\mathrm{KH}_{2} \mathrm{PO}_{4}, 3 \mathrm{mmol} / \mathrm{L}$ malate, and $0.1 \%$ of $\mathrm{BSA}$ ). The substrates were pyruvate $(5 \mathrm{mmol} / \mathrm{L})$, as a glycolytic substrate, and carnitine $(2 \mathrm{mmol} / \mathrm{L})+$ palmitoyl-CoA $(50$ $\mu \mathrm{mol} / \mathrm{L})$, as a fatty acid substrate. Adenosine diphosphate ( $450 \mu \mathrm{mol} / \mathrm{L}$ ) was used to induce state 3 respiration, whereas oligomycin $(1 \mathrm{~g} / \mathrm{mL})$ was used to block adenosine triphosphate (ATP) synthase activity; and hence, state 4o reflects respiration not coupled to ATP synthesis. Maximal oxygen uptake rate (state uncoupled) was obtained by titration of the chemical uncoupler carbonyl cyanide $p$ trifluoromethoxyphenylhydrazone. Oxygen concentrations were recorded, and the first derivative of the oxygen tension changes in time was displayed as oxygen flux. Respiratory control rates were calculated as the ratio between state 3 and state 4 , to determine the coupling of mitochondrial respiration. Oxygen flux per milligram mitochondria was expressed both as absolute value as well as percentage of maximal oxygen uptake rate, as described previously [23]. 
Uncoupling control rates were calculated as the ratio between state 40 and maximal oxygen uptake rate.

\subsection{Calculations}

Optimal thermodynamic efficiency $\left(\eta_{\text {opt }}\right)$ was calculated from state $4 \mathrm{o}$ values as described elsewhere $[17,18]$.

\subsection{UCP3 and marker proteins for mitochondrial density}

Western blotting was used to determine both UCP3 content and to examine protein expression of 5 structural proteins in the individual complexes of the electron transport chain as a reflection of mitochondrial density in tibialis anterior muscle. Mitochondrial density was analyzed in whole muscle homogenates. A rabbit polyclonal antibody detecting mouse endogenous UCP3 (code 1338, kindly provided by LJ Slieker, Eli Lilly, Indianapolis, IN) was used, and UCP3 protein band was visualized by chemiluminescence. A mixture of monoclonal antibodies specific for oxidative phosphorylation (Mitosciences, Eugene, OR) was used to measure mitochondrial density as described before [24]. Amount of protein was expressed as arbitrary units (AU).

\subsection{Fibertyping}

Fibertype was determined by immunohistochemical staining of TA muscle as described before [25] using a mixture of a rabbit polyclonal laminin antibody (Sigma, Zwijndrecht, the Netherlands), a mouse monoclonal heavy chain (MHC) type 1 antibody (A4.840, Developmental Studies Hybridoma Bank, Iowa City, IA), and a mouse MHC type 2A antibody (N2.261, Developmental Studies Hybridoma Bank). Fibers were classified as MHC type I, IIA, or IIB/X based on their MHC I/IIA content.

\subsection{Statistics}

Total caloric nocturnal EE was adjusted for initial body mass. Nocturnal EE was used because this represents the EE during the dark phase, when the animals are most active. Animals were divided into 2 groups based on either a positive or negative residual EE [26]. We used total body mass to correct EE. As total body mass has been demonstrated to reflect lean mass in chow-fed animals of this age, we assumed that a similar correlation was present in our study [27]. Results are presented as mean \pm SD. Statistical analysis was performed using Excel 2003 for Windows (Microsoft Office Excel 2003, Redmond, WA) by unpaired $t$ test with statistical significance threshold set at $P=.05$.

\section{Results}

\subsection{Indirect calorimetry in high-fat-fed C57Bl/6 mice}

Male 12-week-old C57B1/6 mice were fed a high-fat diet (45 energy \% palm oil). Individual food intake, activity, $\mathrm{O}_{2}$ consumption, and $\mathrm{CO}_{2}$ production rates were monitored. Respiratory exchange rate, total $\mathrm{EE}$, and substrate (fat and carbohydrate) -specific EE were calculated from the oxygen consumption and carbon dioxide production rates. Diurnal and nocturnal data were analyzed separately to distinguish metabolic phenotypes characteristic for periods of low (diurnal) and high (nocturnal) activity.

After 3 days of high-fat intervention, individual diurnal EE rates ranged between 386 and $516 \mathrm{cal} / \mathrm{h}$. Nocturnal EE rates were higher than diurnal rates in all animals and ranged between 426 and $600 \mathrm{cal} / \mathrm{h}$. This was in accordance with higher levels of physical activity (diurnal activity, 111.6 breaks; nocturnal activity, 290.8 breaks). Interindividual diurnal and nocturnal EE rates were highly correlated $\left(R^{2}=\right.$ $0.752, P<.01)$, suggesting a consistent intraindividual regulation of energy metabolism. Diurnal and nocturnal RER values varied between 0.739 and 0.890 and between 0.732 and 0.842 , respectively. No differences were found between average diurnal and nocturnal RER values, indicating an equal Fox to CHox ratio. Intraindividual correlation between diurnal and nocturnal RER values was found to be significant but lower compared with total EE levels $\left(R^{2}=0.336, P<\right.$ $.05)$. Individual diurnal and nocturnal fatty acid oxidation rates varied between 185 and $395 \mathrm{cal} / \mathrm{h}$ and between 221 and $384 \mathrm{cal} / \mathrm{h}$, respectively. Diurnal and nocturnal CHox rates varied between 67 and $244 \mathrm{cal} / \mathrm{h}$ and between 51 and $248 \mathrm{cal} /$ $\mathrm{h}$, respectively. Diurnal and nocturnal fatty acid as well as CHox rates were significantly correlated, and correlation was comparable to RER $\left(R^{2}=0.382, P<.01\right.$ and $R^{2}=0.345, P<$ .05 for fatty acid oxidation and CHox, respectively). Respiratory exchange rates reflected food intake, and a strong correlation was found between RER and EI $\left(R^{2}=\right.$ $0.558, P<.01)$. These data indicate a tight intrinsic and individual regulation of EI, EE, and substrate selection.

\subsection{Metabolic characteristics of negative and positive residual EE groups}

Mice were divided into 2 groups based on the average nocturnal EE adjusted for body mass (residual EE, Fig. 1). Body mass did not differ significantly between the mice with a negative residual $\mathrm{EE}$ and a positive residual $\mathrm{EE}$ (negative residual EE, $25.7 \pm 2.8 \mathrm{~g}$; positive residual $\mathrm{EE}, 27.4 \pm 2.4 \mathrm{~g}$ ). Nocturnal food intake was $40 \%$ higher in the positive residual EE group compared with the negative residual EE group (negative residual EE, $6.9 \pm 2.4 \mathrm{kcal}$; positive residual EE, $9.4 \pm 2.1 \mathrm{kcal} ; P=.04$ ). Diurnal food intake tended to be higher in the positive residual EE group, although this failed to reach statistical significance (negative residual EE, $6.2 \pm$ $0.9 \mathrm{kcal}$; positive residual EE, $7.6 \pm 2.0 \mathrm{kcal} ; P=.08$ ). When expressed as a percentage of total EI, nocturnal EI equaled $51.8 \%$ and $55.5 \%$ of total intake in the negative and positive residual EE groups, respectively, indicating no major differences in circadian food intake pattern. As compared with the negative residual EE group, the positive residual EE group was characterized by a higher absolute EE during the night (negative residual EE, $479 \pm 47 \mathrm{cal}$; positive residual EE, $557 \pm 40 \mathrm{cal} ; P<.01$; Fig. 2). Diurnal EE tended to be 

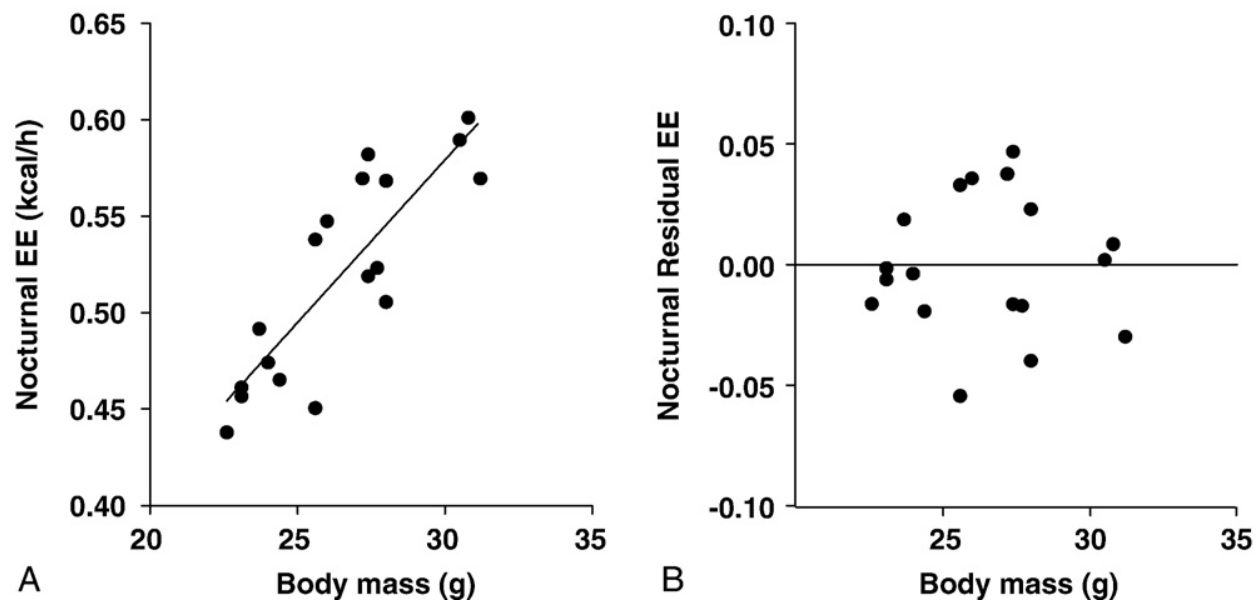

Fig. 1. Animals were divided into 2 groups based upon negative or positive residual EE, after correction of total EE for body mass. A, Regression analysis of body mass and EE. B, Residual plot of regression analysis body mass and EE.

higher in the positive residual EE group, but this failed to reach statistical significance (negative residual EE, $437 \pm 32$ cal; positive residual EE, $467 \pm 37 \mathrm{cal}$; $P=.08$ ). Because EI was $40 \%$ higher, whereas EE was only $16 \%$ higher, in the positive residual EE group, this would indicate that more calories were available for storage in this group. Nocturnal Fox was significantly higher in the positive residual EE group (negative residual EE, $322 \pm 52 \mathrm{cal}$; positive residual $\mathrm{EE}, 361 \pm 10 \mathrm{cal} ; P<.04)$. No differences in Fox were found during the diurnal period. Carbohydrate oxidation did not differ between groups at any part of the day. Interestingly, whereas RER values correlated strongly to EI in the negative residual EE group $\left(R^{2}=0.805, P<.01\right)$, this was not the case in the positive residual EE group $\left(R^{2}=0.166, P=.32\right)$. This indicates that, in the high-EE group, more lipids were oxidized than would be expected on food intake. Total activity levels did not differ significantly between positive and negative residual EE groups at any time of the day, indicating that the higher $\mathrm{EE}$ in the positive residual $\mathrm{EE}$ group was not due to a higher physical activity level. In both groups, activity levels were significantly higher during the nocturnal period compared with the diurnal period for both groups (data not shown).

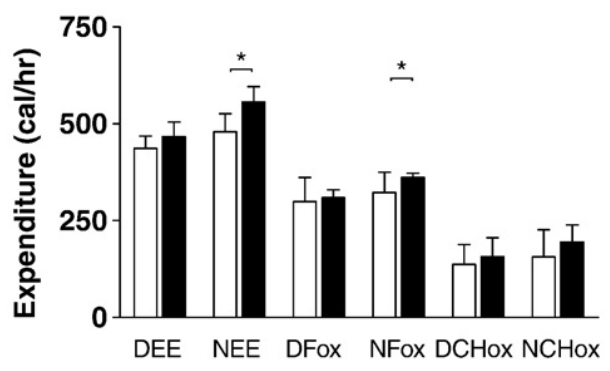

Fig. 2. In vivo metabolic characteristics of the negative (white bars) and positive (black bars) residual EE groups. DEE indicates diurnal EE; NEE, nocturnal EE; DFA, diurnal Fox; NFA, nocturnal Fox; DCO, diurnal CHox; and $\mathrm{NCO}$, nocturnal CHox. Graph represents means $\pm \mathrm{SD} ;{ }^{*} P<.05$.

\subsection{Mitochondrial content and UCP protein content}

No differences were found between positive and negative residual EE groups in UCP3 protein levels (negative residual $\mathrm{EE}, 1.07 \pm 0.50 \mathrm{AU}$; positive residual $\mathrm{EE}, 0.96 \pm 0.21 \mathrm{AU}$; respectively). In addition, OXPHOS protein content did not differ between the 2 groups, indicating similar mitochondrial content (data not shown).

\subsection{Muscle fiber type composition}

The high-EE group showed higher amounts of type IIa, oxidative muscle fibers (negative residual EE, $60.4 \pm 14.6$; positive residual EE, $74.8 \pm 7.7 \%$ of total fibers; $P=.03$ ), whereas the low-EE group had more type IIb, glycolytic fibers (negative residual EE, $38.8 \pm 13.9$; positive residual EE, $25.3 \pm 7.8 \%$ of total fibers; $P=.03$ ). No differences in type I fibers were detected between groups (data not shown).

\subsection{Muscle mitochondrial function of negative residual EE and positive residual EE groups}

Skeletal muscle mitochondria were isolated, and respirometry measurements were performed to assess if muscle mitochondrial function was related to the interindividual variation in EE found between mice on the highfat diet. State 3 respiration was measured with excess availability of substrates and upon stimulation with adenosine diphosphate. State 40 respiration was measured as oligomycin-inhibited leak rate of respiration after inhibition of ATP synthase.

When using pyruvate as substrate, absolute state 3 (negative residual EE, $388.58 \pm 59.42$; positive residual EE, $300.02 \pm 72.43 \mathrm{nmol} /[\mathrm{mg} \mathrm{min}] ; P=.01$ ), state $4 \mathrm{o}$ (negative residual EE, $21.45 \pm 3.65$; positive residual EE, $18.14 \pm 2.26 \mathrm{nmol} /[\mathrm{mg} \mathrm{min}] ; P=.04)$, and maximal uncoupled respiration (negative residual EE, $515.72 \pm 58.81$; positive residual EE, $394.28 \pm 131.39 \mathrm{nmol} /[\mathrm{mg} \mathrm{min}] ; P=$ $.04)$ rates were lower in the positive residual EE group, 
indicating that the overall mitochondrial capacity is lower in this group. However, when expressing the data as relative values (Fig. 3A), no differences were found in state 3 respiration between negative residual $\mathrm{EE}$ and positive residual $\mathrm{EE}$ (negative residual $\mathrm{EE}, 75.1 \pm 5.0$; positive residual EE, $80.0 \pm 14.3$ percentage of maximal uncoupled respiration; $P=.32$ ). Although the uncoupling control ratio seems to be higher in the positive residual $\mathrm{EE}$, this difference did not reach statistical significance (negative residual EE, $4.2 \pm 0.4$; positive residual EE, $5.4 \pm 2.9$ percentage of maximal uncoupled respiration; $P=.19$ ). These data indicate that the control by the oxidative phosphorylation system is similar between groups. This was confirmed by equal respiratory control rates between groups (negative residual EE, $18.3 \pm 2.1$; positive residual EE, $16.8 \pm 4.7 ; P=.38$ ).

Upon fatty acid as a substrate, absolute state 3 (negative residual EE, $98.48 \pm 31.20$; positive residual $\mathrm{EE}, 57.01 \pm$ $14.62 \mathrm{nmol} /[\mathrm{mg} \mathrm{min}] ; P<.01)$ and maximal uncoupled respiration (negative residual EE, $146.00 \pm 32.91$; positive residual EE, $99.23 \pm 32.19 \mathrm{nmol} /[\mathrm{mg} \mathrm{min}] ; P=.01)$ rates were lower in the positive residual EE group, indicating that the overall $\beta$-oxidation is lower in this group. State 4o respiration rate did not differ between the groups (negative residual EE, $19.56 \pm 3.56$; positive residual EE, $18.82 \pm$ $2.23 \mathrm{nmol} /[\mathrm{mg} \mathrm{min}] ; P=.62$ ) when expressed as absolute values. Importantly (Fig. 3B), upon fatty acids also, the relative state 3 respiration tended to be lower in the animals with a positive residual EE compared with the negative residual EE group (negative residual EE, $66.4 \pm 9.0$; positive residual EE, $59.1 \pm 6.3$ percentage of maximal uncoupled respiration; $P=.07$ ). Uncoupling control ratio was significantly higher in the positive residual EE group (negative residual EE, $13.6 \pm 2.1$; positive residual EE, $21.2 \pm 8.2$ percentage of maximal uncoupled respiration; $P=.04$ ). The higher uncoupling control ratio in the positive residual EE animals suggests that a higher fraction of respiration is due to mitochondrial uncoupling in these animals. In accordance, $\eta_{\mathrm{opt}}$ values were lower in the positive residual EE group (negative residual EE, $0.462 \pm 0.01$; positive residual EE, $0.380 \pm 0.027 ; P<.01$ ). The lower degree of coupling was confirmed by a lower respiratory control ratio in the positive residual EE group (negative residual EE, $5.02 \pm 1.23$; positive residual EE, $3.03 \pm 0.74 ; P<.01)$.

\section{Discussion}

To determine the association between individual variation in energy metabolism and skeletal muscle mitochondrial function in high-fat diet-fed C57Bl/6 mice, we performed whole-body indirect calorimetry and muscle mitochondrial function analysis. Individual whole-body energy and substrate oxidation parameters varied considerably between animals, but were consistent within individuals over the diurnal and nocturnal period. This indicates that the processes regulating energy metabolism are specific for individual animals and defined by an individual specific set point. A positive residual nocturnal EE was associated with a higher degree of total uncorrected nocturnal $\mathrm{EE}$ and a lower degree of coupling in mitochondria from skeletal muscle, implying reduced mitochondrial efficiency in vivo. Because variation in skeletal muscle mitochondrial content as well as differences in mitochondrial respiratory capacity may affect EE, both parameters were analyzed. Skeletal muscle mitochondrial content was determined by content of structural proteins of the different complexes of the oxidative phosphorylation cascade and did not differ significantly between the negative and positive residual EE groups. This indicates that the higher whole-body EE levels found in the positive residual EE group did not result from differences in skeletal muscle mitochondrial content. Analysis of mitochondrial function showed that mice with a positive residual EE upon a high-fat diet had the lowest overall mitochondrial oxidative metabolism as indicated by the lower state 3 and maximal uncoupled respiration rates upon pyruvate and fatty acids. Why oxidative capacity is reduced in the group with highest EE is unclear. No differences were observed in OXPHOS protein content, which can be seen as a marker of mitochondrial content; and therefore, the difference is most likely not due to a lower mitochondrial content. Furthermore, a major shift in type $2 \mathrm{a}$ to type $2 \mathrm{~b}$ fibers could result in a less oxidative muscle phenotype. However, animals in the highEE group had a higher percentage of type 2a fibers compared
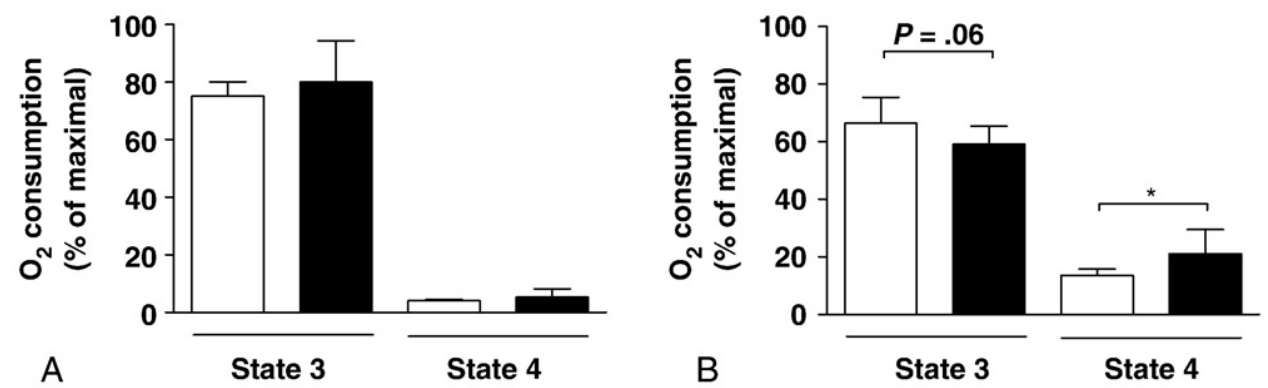

Fig. 3. Respirometry analysis of hind limb-derived mitochondria of the negative (white bars) and positive (black bars) residual EE groups. State 3 and 40 respiration levels were measured using pyruvate (left) and palmitoyl-CoA (right) substrates and expressed as percentage of maximally uncoupled respiration. Graph represents means $\pm \mathrm{SD} ;{ }^{*} P<.05$. 
with the animals in the low-EE group. We decided to investigate if the mitochondria in the high-EE group could be more "leaky," that is, whether a larger fraction of respiration was due to decreased mitochondrial coupling. When using pyruvate as substrate, no differences could be detected in relative state 3 and the relative degree of coupling between the positive and negative residual EE groups. In contrast, using the palmitoyl-CoA substrate, relative state 3 respiration was lower and relative state 4 respiration was higher in the positive residual EE group, which indicated that the degree of coupling of respiration was less in the high-EE group. This indication was confirmed by a significantly lower respiratory control rate in the high-EE group. Thus, apparently, mitochondrial function is substrate specific. Because storage capacity of carbohydrates is limited as compared with fat, maintenance of whole-body carbohydrate balance is more strict [28], which would be in line with more strictly coupled CHox vs Fox.

The $\eta_{\text {opt }}$ has been applied to assess biological processes [29] and has been proposed as a measure of mitochondrial function [30,31]. In the negative residual EE group, the mitochondrial set point is associated with a high degree of coupling and a high thermodynamic efficiency. In contrast, the mitochondrial set point of the positive residual EE group is associated with a low degree of coupling (or higher degree of uncoupling) and low thermodynamic efficiency $[17,18]$. As was mentioned before, the lower degree of mitochondrial coupling was confirmed by the lower respiratory control ratio in the high-EE group. As a result, in vivo mitochondrial ATP synthesis from fatty acid substrates might be less efficient in the positive residual EE group; and more substrate would have to be metabolized to generate the same amount of ATP. This is consistent with the higher levels of whole-body oxygen consumption, carbon dioxide production, and thus EE during high-fat diet intervention that are found in the positive residual EE group. On the other hand, the lower degrees of mitochondrial coupling may be the result of the higher food intake. Higher food intake was found to be correlated to increased CHox but not Fox. Therefore, higher amounts of calories in the form of fat were available for storage in the positive residual EE group. The decreased coupling of fatty acid oxidation may provide a protective mechanism to prevent diet-induced obesity at higher levels of food intake. With the current data, we cannot address the question of whether mitochondrial uncoupling is due to or a consequence of high levels of food intake. Because UCP3 is the main uncoupling protein expressed in skeletal muscle and has been suggested to have an important function in affecting EE by some $[32,33]$ but not others [34-36], UCP3 protein expression was measured. However, there were no differences in UCP3 expression levels between both groups, indicating that, in this study, UCP3 protein content did not account for the differences in muscle mitochondrial uncoupling between groups. These findings are in line with a previous report on a model of reduced mitochondrial coupling, where UCP3 protein levels did not differ from controls [37]. The association between positive residual $\mathrm{EE}$ and decreased degree of coupling at least partly explains the high uncorrected total $\mathrm{EE}$ that is observed in the positive residual EE group. However, the positive residual EE group also consumes some $40 \%$ more food, which would lead to an increase in EE due to the higher thermic effect of food (TEF) [38]. At present, we cannot quantify the exact contribution of the degree of coupling vs the TEF to total EE. However, when assuming that TEF is equal to $10 \%$ of EI and correcting nocturnal EE for this, EE was still significantly higher in the positive residual EE group (data not shown). This indicates that TEF contributes to but does not solely determine the difference in EE between the negative and positive residual $\mathrm{EE}$ group.

Although skeletal muscle is a major contributor to total EE in vivo $[39,40]$ and muscle mass correlates strongly with basal metabolism [41,42], it is evident that other organs with a high metabolic rate, such as the heart, liver, brain, kidneys, spleen, or brown adipose tissue, play a role in determining total EE $[13,43,44]$. It seems unlikely that mitochondrial function is a tissue-specific parameter and varies between organs of the same animal. However, this remains to be established. The individual-specific intrinsic variation in mitochondrial coupling degree occurs on the background of a genetically homogeneous mouse model. Apparently, environmental and/or stochastic events during (early) development play a role in determining a functional set point for mitochondria. Understanding the mechanisms that determine the set point of mitochondria is highly relevant in the context of the generalized overconsumption in Western societies. In conclusion, our data demonstrate a high degree of intrinsic interindividual metabolic regulation in high-fatfed $\mathrm{C} 57 \mathrm{Bl} / 6$ mice. Levels of total $\mathrm{EE}$ as well as substratespecific oxidation rates are set at an individual specific point. In addition, positive residual $\mathrm{EE}$ is correlated to high rates of total EE, higher food intake, and a low degree of coupling in mitochondria from skeletal muscle, implying reduced mitochondrial efficiency in vivo.

\section{Acknowledgment}

This study was supported by the Netherlands Organization for Health Research and Development (ZOn-Mw) (grant: 9120.6050 to M Nabben). The work of P Schrauwen is supported by a VICI grant from the Netherlands Organization for Scientific Research (NWO). This work was supported by grants from the Nutrigenomics Consortium/Top Institute Food and Nutrition, the Center of Medical Systems Biology, and the Netherlands Consortium for Systems Biology established by the Netherlands Genomics Initiative/NWO. Diabetes Research Foundation, Career Development grant: 2005.01.003, NWO Zon-MW, VIDI grant: 917.76.301 and by the Netherlands Organization for Health Care Research Medical Sciences (ZOn-MW project no. 948000 04). 


\section{References}

[1] Burcelin R, Crivelli V, Dacosta A, Roy-Tirelli A, Thorens B. Heterogeneous metabolic adaptation of $\mathrm{C} 57 \mathrm{Bl} / 6 \mathrm{~J}$ mice to high-fat diet. Am J Physiol Endocrinol Metab 2002;282:E834-42.

[2] Judge MK, Zhang J, Tumer N, Carter C, Daniels MJ, Scarpace PJ. Prolonged hyperphagia with high-fat feeding contributes to exacerbated weight gain in rats with adult-onset obesity. Am J Physiol Regul Integr Comp Physiol 2008;295:R773-80.

[3] Savastano DM, Covasa M. Adaptation to a high-fat diet leads to hyperphagia and diminished sensitivity to cholecystokinin in rats. J Nutr 2005;135:1953-9.

[4] Boulange A, Planche E, de Gasquet P. Onset of genetic obesity in the absence of hyperphagia during the first week of life in the Zucker rat (fa/fa). J Lipid Res 1979;20:857-64.

[5] Cleary MP, Vasselli JR, Greenwood MR. Development of obesity in Zucker obese (fa/fa) rat in absence of hyperphagia. Am J Physiol 1980;238:E284-92.

[6] Lin S, Thomas TC, Storlien LH, Huang XF. Development of high fat diet-induced obesity and leptin resistance in $\mathrm{C} 57 \mathrm{Bl} / 6 \mathrm{~J}$ mice. Int $\mathrm{J}$ Obes Relat Metabol Disord 2000;24:639-46.

[7] Ramirez I. High-fat diets stimulate transient hyperphagia whereas wet diets stimulate prolonged hyperphagia in Fischer rats. Physiol Behav 1991;49:1223-8.

[8] Ravussin E, Lillioja S, Knowler WC, Christin L, Freymond D, Abbott WG, et al. Reduced rate of energy expenditure as a risk factor for bodyweight gain. N Engl J Med 1988;318:467-72.

[9] Tataranni PA, Harper IT, Snitker S, Del PA, Vozarova B, Bunt J, et al. Body weight gain in free-living Pima Indians: effect of energy intake vs expenditure. Int J Obes Relat Metabol Disord 2003;27:1578-83.

[10] Butte NF, Cai G, Cole SA, Wilson TA, Fisher JO, Zakeri IF, et al. Metabolic and behavioral predictors of weight gain in Hispanic children: the Viva la Familia Study. Am J Clin Nutr 2007;85:1478-85.

[11] Luke A, Durazo-Arvizu R, Cao G, Adeyemo A, Tayo B, Cooper R. Positive association between resting energy expenditure and weight gain in a lean adult population. Am J Clin Nutr 2006;83:1076-81.

[12] Zurlo F, Larson K, Bogardus C, Ravussin E. Skeletal muscle metabolism is a major determinant of resting energy expenditure. $\mathrm{J}$ Clin Invest 1990;86:1423-7.

[13] Rolfe DF, Brown GC. Cellular energy utilization and molecular origin of standard metabolic rate in mammals. Physiol Rev 1997; 77:731-58.

[14] Anderson EJ, Lustig ME, Boyle KE, Woodlief TL, Kane DA, Lin CT, et al. Mitochondrial $\mathrm{H}_{2} \mathrm{O}_{2}$ emission and cellular redox state link excess fat intake to insulin resistance in both rodents and humans. J Clin Invest 2009;119:573-81.

[15] Bonnard C, Durand A, Peyrol S, Chanseaume E, Chauvin MA, Morio $\mathrm{B}$, et al. Mitochondrial dysfunction results from oxidative stress in the skeletal muscle of diet-induced insulin-resistant mice. J Clin Invest 2008;118:789-800.

[16] Koves TR, Ussher JR, Noland RC, Slentz D, Mosedale M, Ilkayeva O, et al. Mitochondrial overload and incomplete fatty acid oxidation contribute to skeletal muscle insulin resistance. Cell Metabol 2008;7:45-56.

[17] Cairns CB, Walther J, Harken AH, Banerjee A. Mitochondrial oxidative phosphorylation thermodynamic efficiencies reflect physiological organ roles. Am J Physiol 1998;274:R1376-83.

[18] Stucki JW. The optimal efficiency and the economic degrees of coupling of oxidative phosphorylation. Eur J Biochem 1980;109:269-83.

[19] van den Berg SA, Guigas B, Bijland S, Ouwens M, Voshol PJ, Frants $\mathrm{RR}$, et al. High levels of dietary stearate promote adiposity and deteriorate hepatic insulin sensitivity. Nutr Metab (Lond) 2010;7:24.

[20] de Vogel-van den Bosch J, van den Berg SA, Bijland S, Voshol PJ, Havekes LM, Romijn JA, et al. High fat diets rich in medium- versus long-chain fatty acids induce distinct patterns of tissue specific insulin resistance. J Nutr Biochem. In Press.

[21] Peronnet F, Masscotte D. Table of nonprotein respiratory quotient: an update. Can J Sport Sci 1991;16:23-9.
[22] Silva JP, Shabalina IG, Dufour E, Petrovic N, Backlund EC, Hultenby $\mathrm{R}$, et al. SOD2 overexpression: enhanced mitochondrial tolerance but absence of effect on UCP activity. EMBO J 2005;24:4061-70.

[23] Nabben M, Hoeks J, Briede JJ, Glatz JF, Moonen-Kornips E, Hesselink MK, et al. The effect of UCP3 overexpression on mitochondrial ROS production in skeletal muscle of young versus aged mice. FEBS Lett 2008;582:4147-52.

[24] Mensink M, Hesselink MK, Russell AP, Schaart G, Sels JP, Schrauwen P. Improved skeletal muscle oxidative enzyme activity and restoration of PGC-1 alpha and PPAR beta/delta gene expression upon rosiglitazone treatment in obese patients with type 2 diabetes mellitus. Int J Obes 2007;31:1302-10.

[25] Minnaard R, Drost MR, Wagenmakers AJ, van Kranenburg GP, Kuipers F, Hesselink MK. Skeletal muscle wasting and contractile performance in septic rats. Muscle Nerve 2005;31:339-48.

[26] Rosenbaum M, Ravussin E, Matthews DE, Gilker C, Ferraro R, Heymsfield SB, et al. A comparative study of different means of assessing long-term energy expenditure in humans. Am J Physiol 1996;270:R496-504.

[27] Guo J, Hall KD. Estimating the continuous-time dynamics of energy and fat metabolism in mice. PloS Comput Biol 2009;5:1-7.

[28] Flatt JP. Carbohydrate-fat interactions and obesity examined by a twocompartment computer model. Obes Res 2004;12:2013-22.

[29] Feinman RD, Fine EJ. Nonequilibrium thermodynamics and energy efficiency in weight loss diets. Theor Biol Med Model 2007;4:27.

[30] Dumas JF, Simard G, Roussel D, Douay O, Foussard F, Malthiery Y, et al. Mitochondrial energy metabolism in a model of undernutrition induced by dexamethasone. Br J Nutr 2003;90:969-77.

[31] Iossa S, Mollica MP, Lionetti L, Crescenzo R, Tasso R, Liverini G. A possible link between skeletal muscle mitochondrial efficiency and age-induced insulin resistance. Diabetes 2004;53:2861-6.

[32] Cline GW, Vidal-Puig AJ, Dufour S, Cadman KS, Lowell BB, Shulman GI. In vivo effects of uncoupling protein-3 gene disruption on mitochondrial energy metabolism. J Biol Chem 2001;276:20240-4.

[33] de Lange P, Lanni A, Beneduce L, Moreno M, Lombardi A, Silvestri E, et al. Uncoupling protein-3 is a molecular determinant for the regulation of resting metabolic rate by thyroid hormone. Endocrinology 2001;142:3414-20.

[34] Hesselink MK, Mensink M, Schrauwen P. Human uncoupling protein -3 and obesity: an update. Obes Res 2003;11:1429-43.

[35] Echtay KS. Mitochondrial uncoupling proteins - what is their physiological role? Free Radic Biol Med 2007;43:1351-71.

[36] Chan CB, Harper ME. Uncoupling proteins: role in insulin resistance and insulin insufficiency. Curr Diabetes Rev 2006;2:271-83.

[37] Marcinek DJ, Schenkman KA, Ciesielski WA, Lee D, Conley KE. Reduced mitochondrial coupling in vivo alters cellular energetics in aged mouse skeletal muscle. J Physiol 2005;569:467-73.

[38] Even PC, Mokhtarian A, Pele A. Practical aspects of indirect calorimetry in laboratory animals. Neurosci Biobehav Rev 1994;18:435-47.

[39] Ravussin E, Bogardus C. A brief overview of human energy metabolism and its relationship to essential obesity. Am J Clin Nutr 1992;55:242S-5S.

[40] Segal KR, Presta E, Gutin B. Thermic effect of food during graded exercise in normal weight and obese men. Am J Clin Nutr 1984;40:995-1000.

[41] Even PC, Rolland V, Roseau S, Roseau S, Bouthegourd J-C, Tom D. Prediction of basal metabolism from organ size in the rat: relationship to strain, feeding, age, and obesity. Am J Physiol Regul Integr Comp Physiol 2001;280:R1887-96.

[42] Gallagher DE, Berlmonte D, Deurenberg P. Organ-tissue mass measurement allows modeling of REE and metabolically active tissue mass. Am J Physiol Endocrinol Metabol 1998;275:E249-58.

[43] Elia M. Organ and tissue contribution to metabolic rate. Energy metabolism: tissue determinants and cellular corollaries. New York: Raven Press; 1992. p. 61-77.

[44] Wang Z, Heshka S, Wang J, Gallagher D, Deurenberg P, Chen Z, et al. Metabolically active portion of fat-free mass: a cellular body composition level modeling analysis. Am J Physiol Endocrinol Metabol 2007;292:E49-53. 